\title{
aniki
}

Revista Portuguesa da Imagem em Movimento

Portuguese Journal of the Moving Image

\section{0 años de TV Tamix: Entrevista con Genaro Rojas Ramírez, videoasta ayuujk de Tamazulápam del Espíritu Santo, Oaxaca, fundador de la televisora comunitaria TV Tamix}

\author{
Genaro Rojas Ramírez \\ Realizador e investigador independiente \\ narpatk01@gmail.com
}

\author{
Alberto Cuevas Martínez \\ Universidad Nacional Autónoma de México (UNAM) \\ acuevasmartinez@politicas.unam.mx \\ https://orcid.org/oooo-0001-6736-7526
}

RESUMEN Hacia 1990, surgió la organización TV Tamix en el municipio de Tamazulápam del Espíritu Santo Mixe, Oaxaca. Estuvo conformada por personas interesadas en el uso y manejo de los medios radiofónico, videográfico y televisivo. Con cámaras de vídeo, islas de edición y un centro de postproducción analógico, los integrantes de la organización emprendieron el registro de sus manifestaciones culturales. Para difundir los registros audiovisuales, repararon un transmisor de televisión abandonado que pertenecía al Instituto Mexicano de Televisión (IMEVISION), que dio origen al canal 12 "TV Tamix", un medio de comunicación indígena en lengua ayuujk.

PALABRAS CLAVE Audiovisual indígena; México; televisión; TV Tamix.

Hacia 1990, en el municipio de Tamazulápam del Espíritu Santo Mixe, Oaxaca, al suroeste de México, se fundó la Televisora Comunitaria TV Tamix Canal 12 Espacio sagrado. Fue integrada por comuneros, quienes se interesaron por el uso y manejo de tecnologías de comunicación, como la radio, el video y la televisión (Primer Encuentro Nacional sobre Reescritura Tecnológica en México, 2016). Los registros videográficos se realizaron sobre soportes analógicos y abarcaron manifestaciones sociales, culturales, políticas y religiosas, que 
acontecieron en las comunidades del pueblo ayuujk o mixe. ${ }^{1}$ Tras 10 años de actividad continua, TV Tamix salió del aire por motivos políticos y económicos.

La memoria audiovisual del pueblo ayuujk aún yace en sus soportes originales (VHS, 8mm, Betacam, MiniDv) dentro del municipio mixe. El nombre de TV Tamix aún funge como guardián del acervo: a partir de 2010, iniciaron un proyecto de preservación y difusión de su archivo videográfico con base en la transición del sistema analógico al digital. Desafortunadamente, el año pandémico de 2020 paralizó el aniversario por sus tres décadas.

A continuación, se presenta una charla entre el investigador mexicano Alberto Cuevas Martínez - especialista en cine y expresión audiovisual indígena comunitarios - y el videoasta y profesor ayuujk Genaro Rojas Ramírez, quien además de contar con 30 años de experiencia docente, es productor, documentalista, archivista y miembro fundador de TV Tamix. Su cortometraje Estado de Ánimo, protagonizado y dirigido por él mismo, fue seleccionado en el $12^{\circ}$ Festival Internacional de Cine de Morelia en 2014.

Genaro Rojas (GR) - Buenas tardes. Mi nombre es Genaro Rojas Ramírez, soy originario de la comunidad de Tamazulápam del Espíritu Santo, Oaxaca, México, y soy profesor rural de Educación Primaria. Estudié en la Escuela Normal Rural Mactumactzá, Chiapas, y estoy participando en un proyecto de radio y televisión conocido como TV Tamix. En esta ocasión voy a hablar de mi participación en el inicio de un proyecto que se denominó Transferencia de Medios Audiovisuales a Organizaciones y Comunidades Indígenas (TMA). ${ }^{2}$ Fui coordinador del programa Casas del Pueblo: un centro cultural donde se reunían los jóvenes y profesionistas originarios de la comunidad. Ellos me nombraron y estuvimos trabajando la danza, la música, serigrafía, y también abrimos un área de medios, como en el caso del

\footnotetext{
${ }^{1}$ Ayuujk, ayuuk, ayuk, ayöök, ëyuk, ëyuuk o ёyuujk refieren la lengua perteneciente al pueblo originario Ayuukjä'äy o mixe, término que sirve también para nombrar una región ubicada en la sierra Norte, distrito Mixe, al noreste de Oaxaca, con una población de casi 3,000 habitantes.

${ }^{2}$ En 1989, el Archivo Etnográfico Audiovisual del Instituto Nacional Indigenista impulsó un programa (TMA) que consistió en la impartición de cuatro cursos sobre conocimientos básicos para el manejo de tecnología videográfica y producción documental, dirigidos a miembros de organizaciones indígenas (Cuevas 2020).
} 
vídeo y centros de producción radiofónica. Estuvimos recorriendo las instituciones para solicitar apoyos y recursos para promover la cultura ayuujk. Tuvimos la fortuna de encontrar una convocatoria, que decía textualmente lo siguiente:

El Instituto Nacional Indigenista convoca a las organizaciones económicas indígenas al Segundo Curso de Capacitación y Transferencia de técnicas y equipo de video, que se llevará a cabo durante abril y mayo de 1991. Las solicitudes de admisión, junto con una carta donde se explique el interés de participar en este programa, deberá entregarse antes del 15 de marzo en los centros coordinadores indigenistas de su zona, o directamente al Archivo Etnográfico Audiovisual del Instituto Nacional Indigenista, ubicado en la Avenida Revolución 1227, cuarto piso, colonia Alpes, México, Distrito Federal. $^{3}$

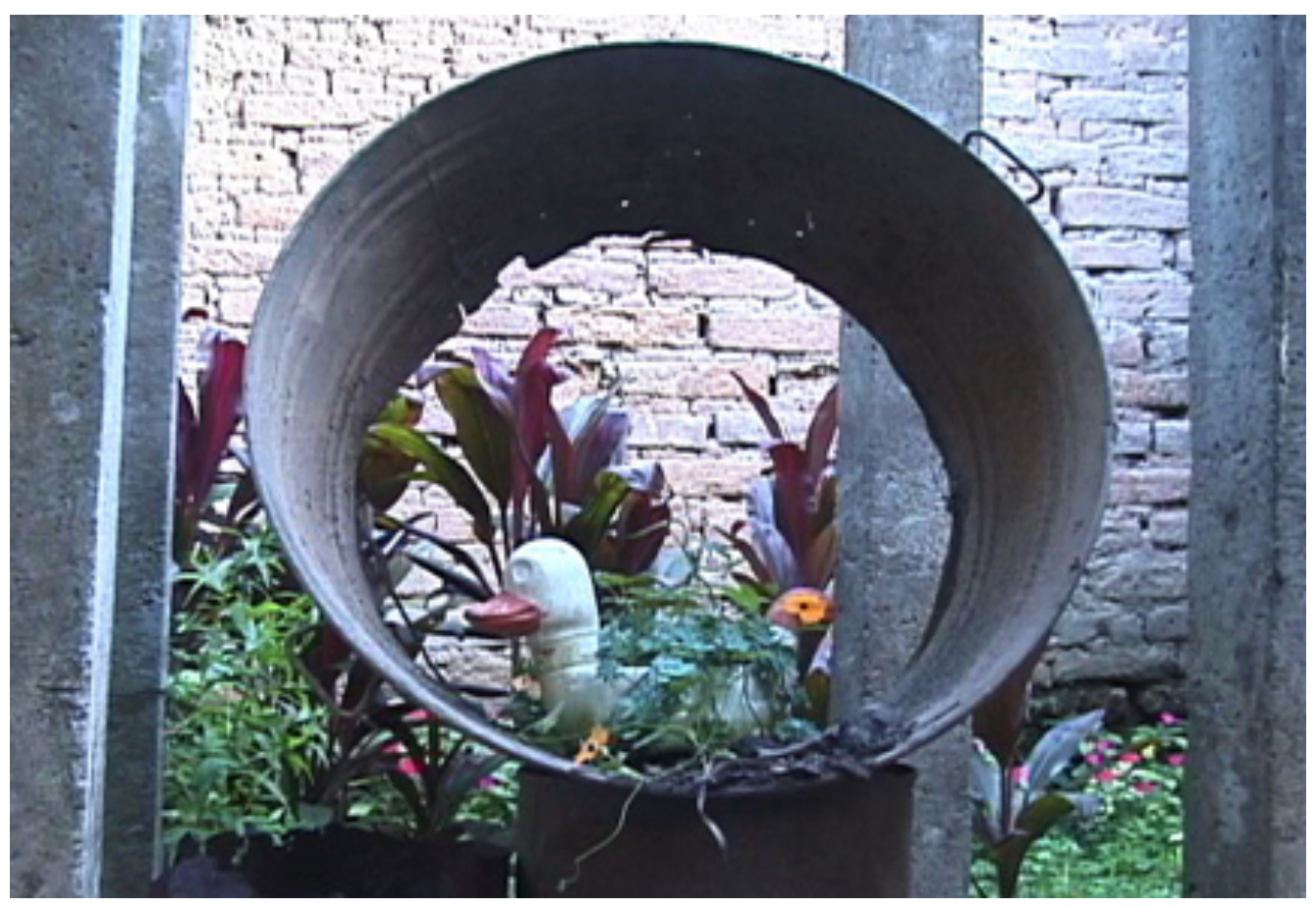

Imagen 1: Fotograma de Estado de Ánimo de Genaro Rojas. Archivo TV Tamix. | C Genaro Rojas.

\footnotetext{
${ }^{3}$ INI 1991, sin número de página. Este documento puede ser consultado en el Archivo TV Tamix (véase bibliografía final).
}

aniki Entrevistas | Interviews 
Nosotros logramos cubrir todos los requisitos de la convocatoria y, finalmente, se envió a dos integrantes de nuestra organización. En esa ocasión le tocó dar su servicio y participar en los cursos de capacitación, que se llevaron en Alférez, Tlacolula, al compañero, también profesor, Victoriano Guilberto Juárez, y al comerciante Aureliano Núñez Martínez. Él estaba como topil ${ }^{4}$ en aquella ocasión, entonces tuvimos que pedirle por favor que fuera. No era fácil disponer de tiempo: fueron dos meses de capacitación. Lo interesante de este programa era que, primero, capacitaban en el uso del cine y el vídeo a nivel profesional, porque usaban cámaras profesionales, y luego en el uso de la isla de edición, que era un sistema analógico.

Los compañeros recibieron el curso. Al finalizar, nos daban estos equipos totalmente gratis, digamos, porque se dotaban para las comunidades; fue así que ya tuvimos aquí nuestro propio centro donde podíamos editar. $\mathrm{Y}$ durante ese tiempo de capacitación, nosotros intercambiamos experiencias con varios compañeros. Cuando los compañeros editaban, también nos explicaban; así fue como se incorporaron otros jóvenes, alrededor de cinco jóvenes, de los que recordamos a: Hermenegildo Rojas, Carlos Martínez Gabriel, Carlos Efraín y otros jóvenes que iban a recibir el curso.

Fue un trabajo complicado pues nos costó mucho aprender a editar en vídeo. Nosotros teníamos que llevar el material a la Ciudad de México para la posproducción, que implicaba el traslado y no teníamos tantos recursos como para ir a la ciudad. Fue creciendo esa necesidad de también tener un centro de posproducción. Y nosotros nos incorporamos a las demás organizaciones que se habían capacitado de las diferentes partes del país, como Michoacán, Chiapas, que eran los más notorios, y todos los de Oaxaca: los compañeros zapotecos de la sierra y del istmo, y también los mixtecos, y así fuimos integrándonos, intercambiábamos experiencias y también había cursos constantes para hablar del uso del vídeo. No fue fácil, porque en realidad no teníamos una idea clara sobre lo que queríamos registrar. Al principio registramos las fiestas, el tequio ${ }^{5}$ y el cambio de autoridades. Nuestros trabajos, poquito a poquito, mejoraron.

\footnotetext{
${ }^{4}$ De origen náhuatl, la palabra topil designa un alguacil.

${ }^{5}$ En México, trabajo colectivo que toda persona debe a su comunidad indígena, y que se hace en beneficio de la propia comunidad, razón por la que no es un trabajo remunerado (nota del revisor).
} 

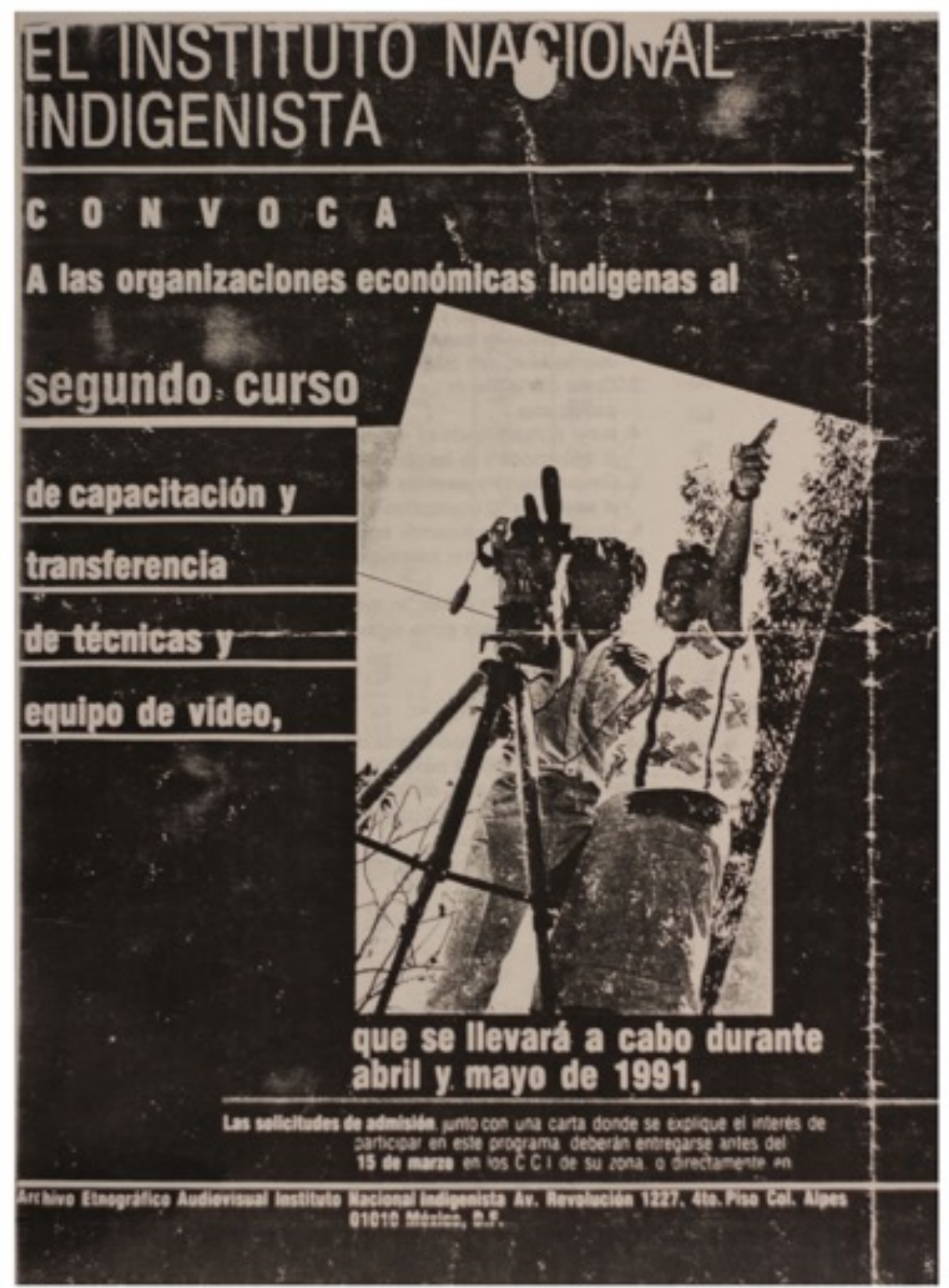

Imagen 2: Convocatoria tipo folleto para el Segundo Curso de Capacitación y transferencia de técnicas y equipo de video, 1991, impresión. | Fuente: Archivo TV Tamix. 
El trabajo que más se promovió, de los que nosotros logramos producir, fue Moojk (Maíz): es el que más se ha difundido, incluso a nivel internacional; luego estaba Këdung Ajdk (Servir al pueblo). Entonces ya teníamos como un paquete de trabajos bien hechos, entre ellos Fiesta animada, que es un género de grabar fiestas. Todo esto era, digamos, a corte directo, no era posproducido. Entonces nació la inquietud de tener un centro de vídeo donde pudiéramos posproducir. Les voy a leer un texto sobre la inauguración del Centro Nacional de Vídeo Indígena (CVI), así se llamó: "el centro prestará servicios de producción y postproducción a los miembros de las organizaciones capacitadas y a los videoastas indígenas independientes del sur y sureste de la República, mediante talleres de reflexión y la creación de una organización independiente de videoastas indígenas."

Así fue como nosotros nos incorporamos al Centro Nacional de Vídeo Indígena. Allí, nosotros vimos que era necesario tener una participación más activa y también comisionamos a un joven de nuestra organización, Carlos Martínez Gabriel, quien se capacitó en la postproducción... entonces TV Tamix tuvo la fortuna de tener todo el equipo de postproducción, y pues participábamos en los festivales y talleres. Así fue como nos incorporamos a este proyecto de TMA, nosotros participamos en el segundo curso.

\section{Alberto Cuevas (AC) - ¿Qué fue el proyecto de Transferencia de Medios Audiovisuales a Organizaciones y Comunidades Indígenas?}

GR - Bueno, en esta ocasión voy a hablar sobre la experiencia del uso del vídeo en comunidades indígenas. El proyecto de transferencia de medios fue una experiencia muy interesante porque, por un lado, la institución que lo promovió tenía, en su mayoría, la experiencia del cine etnográfico. Uno de los maestros fue Alfonso Muñoz Jiménez, quien tenía mucha experiencia en fotografía y cine. Dentro de los maestros está Carlos Cruz de la UNAM. Era gente que tenía experiencia de trabajar en comunidades. Ellos veían la necesidad de que los propios originarios de los pueblos pudieran registrar su vida, su historia. Entonces la propuesta era muy buena pero pues había dos tendencias. Según los libros que hemos leído, unos decían "no podemos darle material a esa gente indígena que, pues, no sabe leer, no sabe escribir y el cine necesita profesionalismo"; y otros afirmaban, "hay que capacitarlos, tenemos qué dotarlos de equipo" (Anaya 1990; Cuevas 2021).

aniki Entrevistas | Interviews 
Por fin se logró autorizar dicha iniciativa y se iniciaron los primeros cursos. Nosotros somos de la segunda generación y nos dimos cuenta de lo complicado que es hacer cine... hacer documentales. Primero, pues era mucho la cuestión de la etnografía en el cine de blanco y negro, pero pues gracias a la llegada del vídeo, del Súper VHS, cambió el panorama de hacer registros, y pues ya pudo ser más accesible, como la cámara, una cámara que ya podía manejarse, maniobrarse, y nosotros tuvimos esa fortuna de tener gente que se capacitó en su manejo. Pero donde se ponía complicado el asunto era el contenido, la forma de la narración. Nos presentaron varios vídeos que, pues sí eran clásicos, como los elaborados por el Instituto Nacional Indigenista y el Archivo Etnográfico Audiovisual.

Nos mostraron películas como Peleas de tigres. Una petición de lluvia nahua (1987) de Alfredo Portilla y Alberto Becerril, o En clave de sol (1981) de Ludwik Margules, que se había grabado en la región mixe de Tlahuiltoltepec, Oaxaca. Entonces como que ese género, pues estaba bien, y entonces nosotros queríamos retomar eso: por un lado, la forma de hacer cine era interesante porque nos dieron ejemplos de que se había hecho con los pueblos originarios. Pero también nosotros nos confrontábamos con la comunidad, ¿qué era lo que realmente le interesaba a la comunidad? En dicha ocasión, la comunidad andaba con sus conflictos internos, de tierras, el asunto de las fiestas... Entonces nosotros vimos nuestra problemática; por un lado, la exigencia del pueblo y por otro, la exigencia de la institución, porque teníamos que ir a congresos, reuniones, festivales, y nos pedían trabajos, y nosotros muy lentos porque, la verdad, nos costó mucho hacer un programa de vídeo y los pocos que hacíamos, pues los llevábamos y explicábamos las dificultades. Sin embargo, se hicieron muy buenos trabajos como los que les mencioné... algunos hechos con tripié, porque era mucha la exigencia de que debe estar muy bien hecho el trabajo. Hicimos varios cortes: nos tardamos dos, tres años, en hacer un programa. Era muy largo. Pero también nosotros, por iniciativa nuestra, dijimos bueno, pues hagamos programas para el exterior y también para nuestra gente. Ultimadamente quienes lo van a usar somos nosotros.

Claro, las exigencias institucionales eran otras. Entonces tuvimos que aprender a trabajar estos dos contextos, dos formas. Nosotros, dentro de lo que más ha generado polémica como una propuesta alternativa, o más bien, que rompió el género, fue Jaripeo (producción colectiva, 1992) un cortometraje de tres minutos donde se hacen juegos con el 
toro, la pirotecnia y la música. Entonces cambia totalmente la forma de editar y nosotros nos fuimos más por ese lado de estar explorando, estar utilizando nuevas formas de cómo expresarse en el medio.

Lo que se debatía mucho era el asunto político: en Ecuador, en otros pueblos que estaban en lucha como Bolivia, estaban más metidos con los vídeos de marchas, bloqueos, enfrentamientos, cosa que en México todavía no llegaba. Nosotros estábamos con nuestras fiestas, vivíamos, digamos, en la tranquilidad. Nuestros programas no eran tan fáciles para que fueran aceptados en los festivales; decían, "bueno, ustedes, ¿de qué luchan si nada más es pura fiesta?” Entonces tuvimos que darle un discurso político a nuestros documentales y decir, "bueno, pues, también luchar por la autonomía, la autodeterminación es con las fiestas: es propia, es de nosotros -nuestros músicos y danzantes- es parte de [aquello por] lo que luchamos." Entonces tuvimos que darle un discurso político, y sobre todo, la diversidad, que éramos tan diversos a pesar de que fuéramos de pueblos originarios, pero teníamos lo nuestro.

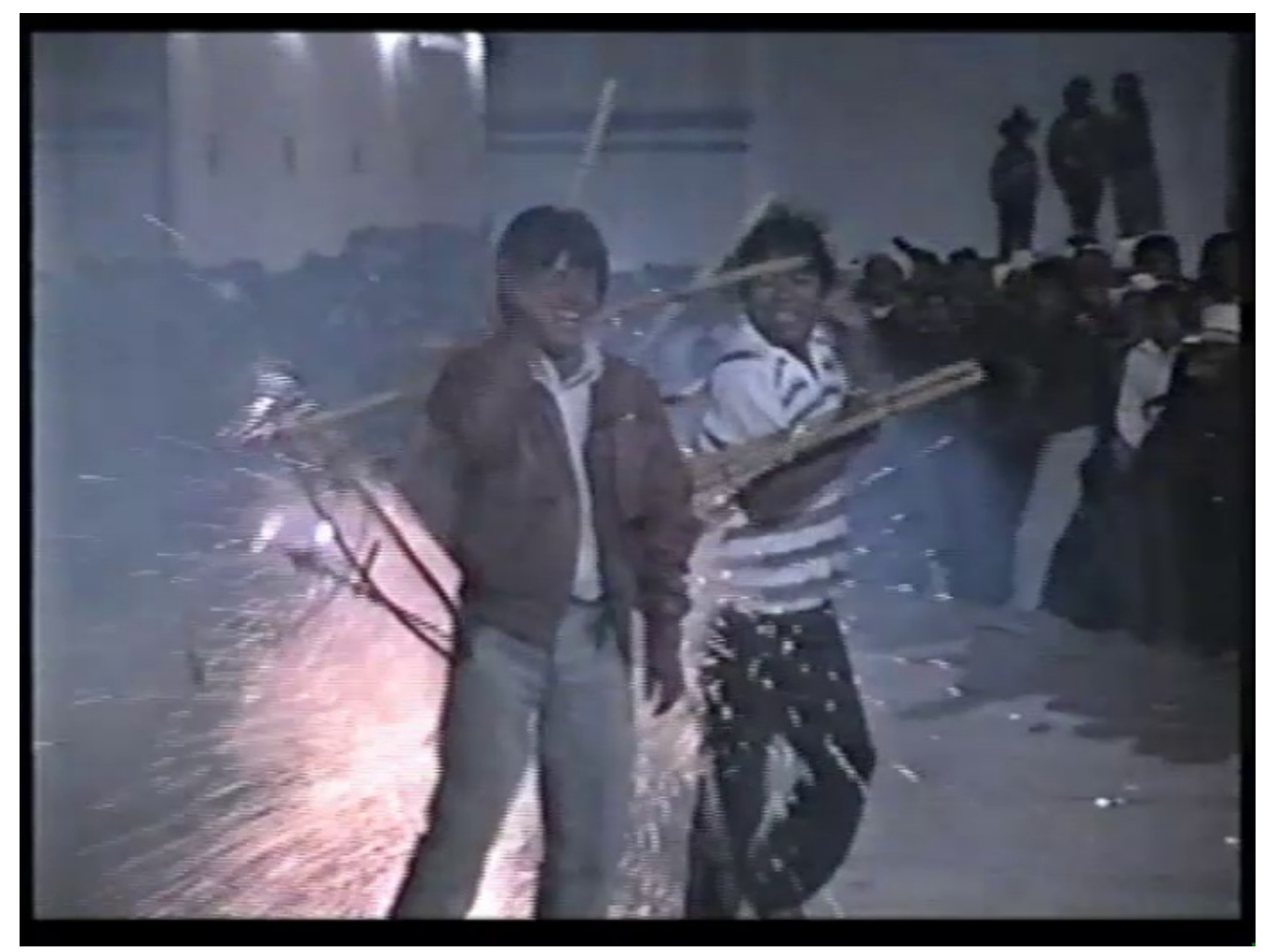

Imagen 3: Fotograma de Jaripeo, producción colectiva. | Fuente: Archivo TV Tamix. 
Así fue como empezamos a trabajar por nuestra cuenta. Pero sí fue muy interesante el proyecto porque, al menos, teníamos asesores, gente que nos hacía la crítica, recomendaciones, tuvimos que leer libros, asistir a otros cursos para poder estar al nivel profesional de lo que es el cine y el vídeo. Tuvo sus fases complicadas porque, por un lado, los compañeros decían: "es que trabajar con puro tripié, no te mueves mucho, y nosotros queremos más acción." Entonces tuvimos que aprender a usar la cámara: saber estabilizarse y entrar en movimiento. Regularmente los vídeos que se estaban empezando a producir por las organizaciones eran [con tomas] muy fijas: gente sentada. Y nosotros dijimos, "no, tiene que ser en movimiento porque si no hay acción, como que es muy aburrido." Entonces se tuvo que explorar y usar la cámara en diferentes tomas, secuencias, movimientos; los jóvenes se capacitaron muy bien en ese terreno. Éramos invitados en otros espacios por nuestra forma de producir. Pero, desgraciadamente, llega la fase crítica donde aparece el Ejército Zapatista de Liberación Nacional (EZLN). ${ }^{6}$ Entonces las comunidades indígenas nos empiezan a ubicar de ese lado y el proyecto tuvo que pararse: el programa ya no dio los recursos pero, sin embargo, logramos varias propuestas, como el Centro Nacional de Vídeo Indígena, donde logramos tener un equipo de posproducción ydonde se capacitaba e intercambiaban experiencias. Antes un centro de producción era enorme; era un equipo grandísimo donde tenían monitores, computadoras y una persona que supiera de eso, pues era complicado; sin embargo, se logró y nosotros tuvimos ahí un joven que sí logró capacitarse.

TV Tamix fue una de las organizaciones más completas. Nosotros nos fuimos por el lado técnico: tener y respetar la cuestión de los encuadres, los enfoques, tener bien los escenarios. A nivel técnico, estuvimos a la altura; a nivel social, incorporamos a mucha gente que era invisible, como campesinos, artesanos, gente que casi no se le graba; regularmente, cuando venían [externos a grabar], siempre era al director de la banda musical, el presidente municipal o las autoridades. Nosotros dijimos: vamos a hacer visibles a otros actores, como el campesino, el comerciante, y así fue como nuestro trabajo tuvo ese

\footnotetext{
${ }^{6}$ Insurgencia integrada por pueblos mayas de Chiapas (tzeltal, tzotzil, chol y tojolabal). Se sublevaron la madrugada del $1^{\circ}$ de enero de 1994, cuando el gobierno mexicano de Carlos Salinas de Gortari celebraba la entrada en vigor del Tratado de Libre Comercio de América del Norte (TLCAN). Su objetivo era la transformación revolucionaria del país en una república socialista, bajo las demandas de trabajo, tierra, vivienda, alimentación, salud, educación, libertad, justicia y paz (Secretaría Ejecutiva CNDH, sin fecha).
} 
enfoque social y comunitario. Entonces cubrimos los aspectos fundamentales para tener un medio de comunicación propio. El finado maestro Alfonso López García, que fue mi tío y que en paz descanse, nos inculcó el uso de la lengua ayuujk.

AC - Cuando empezaste a aprender esta tecnología videográfica, ¿la sentiste ajena a las maneras de expresión de aquí, que normalmente se tienen en Tamazulápam del Espíritu Santo?

GR - En la época de la conquista, nosotros como mixes tenemos esa historia de que nunca fuimos conquistados. Entonces éramos como más conservadores porque cuidábamos mucho nuestra forma de ser, de vivir, de hablar, y fue un momento donde resistimos con fuerza. Entonces pensábamos que la tecnología podía dañar nuestra cultura, que podía alterar nuestra vida. Y pues la televisión, efectivamente, eso ha hecho, ¿no? Ha alterado la vida cultural y social de los pueblos, la televisión comercial. Yo conocía el cine porque fui a la Normal ${ }^{7}$ y en aquella época, me tocó ver el cine hecho por los movimientos sociales, del Frente sandinista y el movimiento de $1968 . .^{\circ}$ De alguna manera tenía otra visión que se podía también utilizar para fines comunitarios y sociales. Pero sí era un peligro siempre porque [dice la gente retratada], “¿para qué lo quieren? ¿qué quieren hacer con nuestra imagen? ¿qué es lo que buscan? ¿cómo nos quieren representar?”

En los cursos que se recibieron, mostraron vídeos o películas sobre comunidades indígenas, hechas por Emilio "Indio" Fernández donde participaron actrices. ${ }^{9}$ Veíamos una falsa representación, ¿qué era lo que realmente buscaban? Había esa desconfianza contra el Estado, era un choque contra una política de integración: integrarse en la modernidad,copiar esquemas de producción cultural y de comunicación. Nosotros caímos en ese juego; también estábamos pensando en crear locutores, conductores de radio y televisión, como

\footnotetext{
${ }^{7}$ La Escuela Normal Rural Mactumactzá - ubicada en el estado de Chiapas, al sureste de México - surgió en 1931 como un centro educativo de estudios superiores para alumnos de origen campesino. Su objetivo se centra en la formación de profesores de Educación Primaria (ENRM, sin fecha).

${ }^{8}$ En 1979, el Frente Sandinista de Liberación Nacional de Nicaragua derrocó a la dictadura encabezada por Anastasio Somoza; por su parte, una década atrás, en México aconteció un gran movimiento estudiantil que culminó en la trágica matanza de Tlatelolco, el 02 de octubre de 1968. Ambos acontecimientos eran lugares de memoria recurrentes para la militancia social.

${ }^{9}$ Emilio Fernández Romo (1904-1986) fue un director, actor y guionista mexicano de ascendencia kikapú (pueblo originario del norte de México, con residencia al sur de EE.UU). Es aclamado por su prolífica trayectoria como realizador del período conocido como Época de Oro del Cine Mexicano, que contribuyó a la conformación de un imaginario indigenista folclórico (nota del revisor).
} 
Raúl Velasco. De alguna manera ya teníamos ese contacto y pues ese era el riesgo porque podías caer en una reproducción de la televisora comercial. Pero el cine iba también por su rumbo, como el caso de TMA, que daba a conocer un México totalmente distinto, pero que era un México de todos modos visto por una mirada ajena, no por la mirada de los propios nativos, originarios o las propias comunidades como nosotros los mixes.

Fue un debate constante, nosotros dijimos: tenemos que hacer algo propio, lo que estamos haciendo es para nuestros nietos, nuestra familia, nuestro pueblo. Teníamos aquí antropólogos bastante formados, como los profesores Daniel Martínez Pérez y Alfonso López, quienes ya hablaban de la importancia de una cultura propia como es el ayuujk: la lengua, la música, los cuentos, las tradiciones... y eso fue lo que retomamos en las producciones de forma prioritaria. Fue un choque cultural fuerte: la tecnología siempre es un riesgo, como sigue siendo hoy Internet, que también puede ser un instrumento de dominación. El riesgo era que nosotros llegáramos a dominar a nuestra propia gente, o sea, tener este monopolio. Nos dimos cuenta de que es un medio de comunicación social, un medio comunitario, y pues nosotros nos integramos a la comunidad como dando un tequio: ${ }^{10}$ para poder preservar lo que hacían nuestros ancestros. Afortunadamente hoy tenemos un archivo donde guardamos las memorias, los recuerdos de nuestros abuelos y abuelas, de las personas del campo...
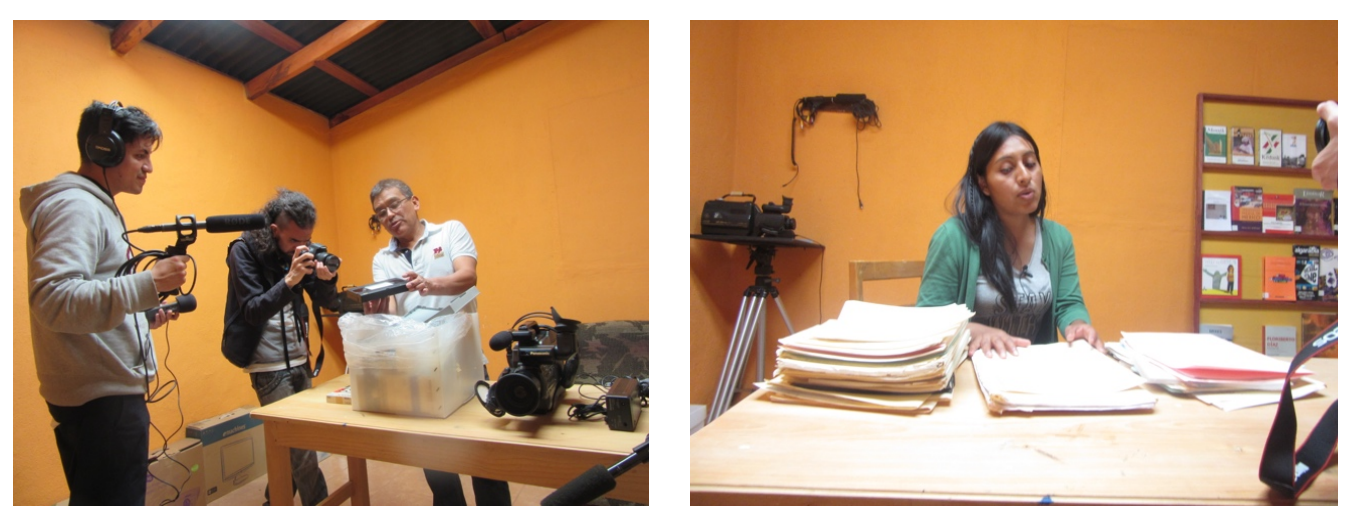

Imágenes 4 y 5: En la primera (de izquierda a derecha): Alberto Cuevas, Áaron Álvarez y Genaro Rojas en el Archivo TV Tamix; en la segunda: Rosita Román, investigadora ayuujk dentro del Archivo TV Tamix en Tamazulápam del Espíritu Santo Mixe. | Colección Genaro Rojas.

\footnotetext{
${ }^{10}$ Palabra derivada del náhuatl tequitl, que equivale al trabajo o tributo. Remite a una costumbre mesoamericana donde los miembros de una región cooperan en una tarea que beneficie a la colectividad.
}

aniki Entrevistas | Interviews 
AC - ¿Cuáles eran tus actividades como asistente de una producción o productor? ¿Cómo era un día de trabajo en producción para Genaro?

GR - Cuando teníamos, digamos, un staff de quince gentes, éramos dos grupos que nos dividíamos: los profesionistas - que éramos adultos, personas que teníamos una profesión - y los jóvenes, que eran estudiantes. Entonces el debate era que teníamos que hacer la producción por especialización: un camarógrafo, sonidista, el de producción, el director... todo lo que es el esquema de producción de cine. Otros decíamos, "tiene que ser entre todos." Porque muchos decían, "yo sólo me voy a concentrar en la cámara... yo ya no me meto en otras cosas, ustedes vean lo de las locaciones, vean los guiones, yo nada más llego con la cámara." Era un debate si nos especializábamos o trabajábamos así como en las comunidades: en comuna, en común, de forma comunal. Probamos ambas experiencias y funcionaron. Hay trabajos muy bien hechos por especialización y en los créditos aparecen claramente - quién fue el que tuvo la cámara, el de sonido, el de producción, el de posproducción. También hubo trabajos hechos por compañeros que no fueron a la capacitación, como Vicente Antúnez López. Él nunca se capacitó y nada más lo único que aprendió fue [a oprimir el botón] Rec y agarró la cámara por su cuenta: grabó lo que quiso en las fiestas, y eso funcionó muy bien. Era bien padre porque otros ni recibieron el curso y hacían cine, y hacían muy buenas producciones. Creo que, dentro del cine, es mucho más realista y nosotros presionábamos al actor porque los obligábamos a que saliera lo mejor, y se ponía más tenso. Tuvimos que aprender a relajarnos, a tener confianza, y explicarles que era parte de la vida cotidiana. O sea, lo que íbamos a hacer es lo que hacemos diario, "no se preocupen: ustedes hablen, muévanse como viven, no se preocupen por nosotros." Así fue como liberamos la forma de trabajo. Por un lado, sabemos que para el cine sí se necesita mucho profesionalismo, porque hay que conocer muy bien el asunto de la luz, la composición y los temas. Sin embargo, llegó un momento en que dijimos: que cada quien agarre la cámara y que produzca. De repente veías a alguien grabando básquetbol, otros a su tío, algunos más retrataban un día normal, el mercado. Eso permitió que nosotros tuviéramos acceso a más registros. 


\section{AC - iRecuerdas las producciones que hiciste $o$ en las que participaste durante TMA?}

GR - Como yo era el que coordinaba la cuestión de la gestoría platicar con las autoridades, explicarles al pueblo - yo era más "político". Tenía el servicio de secretario municipal y luego participaba en los diálogos para resolver los conflictos agrarios. Entonces tenía comisiones más políticas entre las comunidades como un servicio para resolver los conflictos de tierra sobre las colindancias con la comunidad de Tlahuiltoltepec (Barrera 2017). Yo me centraba más en eso. Entonces les decía: pues los jóvenes van a hacer un registro, van a hablar sobre el maíz, van a hablar sobre el conflicto agrario y pues vamos a dejar que graben. Entonces yo me dedicaba a sensibilizar la gente: ya los muchachos, estaban trabajando con la cámara y la edición.

Realmente estuve mucho tiempo sin hacer mucha producción: ellos en las reuniones, entre el colectivo, pues se ponían a discutir cómo iban a ser los programas, de qué manera podrían retratar a nuestra gente. Realmente yo conocí a mi pueblo por vídeo, o sea, muchas de las producciones que he visto - por ejemplo, del maíz, los chamanes, los campesinos - casi nunca los vi personalmente sino que los conocí por vídeo... porque yo andaba en otros lugares, y mientras los jóvenes grababan en otros espacios. Cuando yo tenía tiempo, agarraba la cámara o ayudaba. Inicialmente era yo asistente, yo creo que eso ha sido mi destino porque he sido asistente en casi todos los documentales, pues yo veía el asunto de que el equipo estuviera completo, si faltaba un cable, que hay que ir a comprar un cable, que hay que tener listo el equipo de producción. Además, hay que estar al tanto con los tamales y la comida. ${ }^{11}$ Mucho tiempo me dediqué a ser asistente aunque después me ponían que yo era el director. Realmente no lo era pero necesitábamos poner a alguien ahí y ponían mi nombre. Ya cuando veía que nadie ocupaba la cámara, me grababa a mí mismo, hacía ejercicios, y pues parte de mis producciones son eso: que yo mismo me grabo y entonces soy el actor.

Empecé a trabajar más en serio con la cámara y comencé a editar con mi amigo Victoriano. Así fue mi vida con la transferencia de medios.

\footnotetext{
${ }^{11}$ Esta frase equivale a las funciones de un catering cinematográfico, esto es, proveer insumos alimenticios a los miembros de la producción. Los tamales son un alimento típico mexicano que consiste en una porción de masa envuelta en hoja de plátano o maíz, generalmente relleno de carne y salsa.
} 
También era yo el que daba el debate, la discusión en los foros, en las ponencias, pero sí me iba rezagando en la cuestión técnica. En lo que yo aprendía cámara, los jóvenes ya estaban en edición; en lo que yo hacía edición, los demás ya estaban en posproducción. Entonces, sí me costó mucho entender el lenguaje del cine. Afortunadamente pudimos integrar un solo lenguaje. Nos entendíamos en la producción y, después, liberamos prácticamente nuestra forma de producir: ya no había tanta seriedad, sino mucha confianza, pues grabábamos risas y la cámara logró, por fin, pasar desapercibida, porque ya nadie sabía quién tenía la cámara, de repente la tenía Roberto o Rafael o Genaro, o sea, la gente se descontroló pues ya no tenía esa preocupación de saber quién cargaba la cámara o quién andaba grabando a quién. Llegó esa fase comunitaria con una cámara. Y pues era bien interesante porque cada quien tuvo su mirada. Eso fue lo que más me gustó y creo que es una de las experiencias más bonitas que hay en México y en el caso TV Tamix: que sí se puede hacer una producción colectiva y es muy rico porque la mirada es diversa.

\section{AC - ¿Cómo surge TV Tamix?}

GR - Cuando nosotros nos dimos cuenta de que ya teníamos centro de posproducción radiofónica - que teníamos nociones de radio y vídeo nos percatamos que había un transmisor abandonado en la secundaria técnica y una antena repetidora de una televisora estatal mexicana. Lo abandonaron porque no llegaban las señales de televisión. Nosotros logramos repararlo con ayuda de unos técnicos del Canal 9 de televisión de Oaxaca, unos ingenieros que vinieron a darnos un curso, y entonces empezamos a usar el transmisor. Entonces ya nos llamamos televisión porque ya teníamos un transmisor.

AC - Rescatan el transmisor, tienen el equipo que previamente les había facilitado el INI a través de TMA y, entonces, ¿cómo comenzaron a hacer producciones que se apreciarían en la localidad?

GR - Bueno, es que TMA era un proyecto legal, un proyecto que el Estado siempre estaba vigilando. Y luego los del Instituto Nacional Indigenista (INI) y el Archivo Etnográfico Audiovisual (AEA) estaban dándole seguimiento a los avances de este proyecto. Y cuando ellos se dan cuenta que nosotros estábamos haciendo televisión, les entra una preocupación, dicen, “oye, pero, ¿̇a quien le pidieron permiso?" "Pues al presidente municipal y la asamblea". Respondieron, "pero es que ustedes están transmitiendo por televisión”, “pues sí, pero ya le dijimos 
a la autoridad." "No", argumentan, "es que hay una ley, de eso se encarga la Secretaría de Comunicaciones y Transportes, hay que tener permiso o concesión.” Les entró la preocupación, “¡no! los pueden multar o meter en la cárcel”, a lo que respondimos, "pero si estamos en nuestro territorio, o sea, es nuestro pueblo, este espacio, por eso es que después nos llamamos espacio sagrado. Ya luchamos por nuestros terrenos, nuestra tierra y territorio, pues también estamos luchando por el espacio." Fue una lucha por tener el control de los medios. De las ondas, a nivel comunitario podemos usar nuestro espacio. Nos entró la preocupación después porque la gente pensaba que nosotros íbamos a México a usar los transmisores desde allá. Entonces estos cuates dicen, “¿cómo es que lograron ir hasta México para hacer una transmisión?” Pero los niños son más curiosos pues llegaron a la secundaria y dicen, "pues si ellos están transmitiendo desde la secundaria." O sea, ubicaron el lugar. Fue una preocupación y es parte de la historia. Cuando vino un gobernador le dijimos, "oye ¿por qué no inauguras nuestra emisora?" Entonces el gobernador en turno era Heladio Ramírez López.

\section{AC - ¿Y TMA?}

GR - Hablando del programa de Transferencia de Medios, era complicado porque, por un lado, era bueno: teníamos la estructura, el equipo profesional, un equipo de posproducción; uno en el estado de Oaxaca, en la capital, y otro en Michoacán. ${ }^{12}$ Entonces ya era un gran avance, incluso se hablaba de una organización de videoastas indígenas en el país. O sea, nosotros ya nos estábamos consolidando... Había todo un movimiento fuerte del video indígena pero también nosotros decíamos, "bueno, ¿y por qué nos van a encasillar a un vídeo indígena?" O sea, “¿cuál es la diferencia con los otros medios?” Era todo un debate porque, por un lado, nosotros afirmábamos, "eres un videoasta o eres un cineasta indígena." Eso también lo pensamos, "oye, ¿pero por qué?” O sea, "somos parte de una sociedad." Hubo mucho debate porque decían, "es que estos son los videoastas indígenas". Cuando la gente decía, "va a haber una proyección de video indígena”, respondían "ah, pues son los de Tamazulápam, los de las comunidades", también era como una forma de discriminación.

Nosotros tenemos que lograr que nos incorporen al cine, a los medios, al video, y pues tuvimos la fortuna de estar en otros festivales que no

\footnotetext{
${ }^{12}$ En relación con los Centros de Vídeo Indígena.
} 
eran promovidos por TMA o el INI: hemos participado en el Festival de Cine de Guadalajara y Morelia; estuvimos en otros espacios como el Museo de Arte Moderno de Oaxaca (MACO) y otros recintos independientes. Nos fuimos abriendo espacio con nuestras propuestas de cine, de proyección, y hemos llegado a ese nivel de hacer documentales, ficciones o combinar ambas. Llegó un momento en que la gente no lograba distinguir si era documental o era ficción. Que también es otro debate muy fuerte porque unos decían, "no, pues hay que hacer ficción"; otros, "es mejor documental". Nos ha costado mucho abrir ese espacio y pues fue un período muy interesante en México, del uso de los medios. Posteriormente fuimos a trabajar con las bases de apoyo del EZLN. Nosotros estamos centrados en el uso del campo: no nos interesó grabar la comandancia, sino, más bien, la gente del campo, en las comunidades, cómo estaban viviendo. Ellos también empezaron a hacer sus documentales sobre el maíz, sobre lo que nos identifica como pueblos originarios.

Esta experiencia de Transferencia de Medios fue muy interesante. Por un lado, porque ha sido estudiada por antropólogos, etnógrafos o gente que ha estudiado el uso del cine o el vídeo en las comunidades originarias: de Norteamérica, Canadá, toda Latinoamérica y Europa. Sabemos que hay todo un movimiento del cine etnográfico pero que después se pasó al vídeo. Había como una confusión: por un lado, ¿qué era el cine? ¿el formato y no hablar del contenido de cine, que es en sí la historia que se construye?, y sobre todo, ¿cómo dar a conocer una realidad? ¿cuál es la realidad? ¿cómo podrías lograr que fuera lo más real posible? Porque uno de los riesgos que se corre es que, cuando actúas, puedes sobreactuar. Y también puedes dar la imagen que tú quieres. Nosotros optamos por una realidad. Dijimos, "bueno, pues vamos a salir como estamos, ¿para qué nos maquillamos? vamos a entrarle como estamos, con la ropa que tenemos." Afirmamos, "esta es nuestra gente y si se quiere parar a mi lado [mientras sucede la grabación], pues que se pare; no tengo por qué estarle quitando, tú no o tú sí.”

La lucha sobre cómo registrar la realidad pero, ¿qué es la realidad y cómo obtenerla? Ese debate ha sido muy fuerte entre los profesionales, y nosotros como comunicadores de las comunidades, que nos fuimos capacitando con este programa de TMA, nos enriquecimos mucho porque tuvimos otra mirada: ya nos fijamos en nuestras paredes, en nuestras veredas, empezamos a darle importancia a lo que tenemos. No 
era un estudio lo que necesitábamos o las salas de cine como Churubusco, pues toda representación se hacía en una sala. Aquí eran actores reales, gente real. Desde ahí tuvimos, tal vez, uno de los impactos más fuertes, pues retratábamos gente de carne y hueso, con sentimientos. Para nosotros, el cine pasó a ser parte de nuestra vida y cuando empezamos a ver que habíamos grabado a nuestros músicos, a nuestros abuelos que se habían muerto, entonces nos empezó a generar una reflexión de que esa historia era importante, pero también nos causaba dolor porque decíamos, "es que él ya no vive, ¿por qué lo vamos a volver a mostrar?".

Era un choque fuerte porque no podías volver a ver a tu papá que ya estaba muerto, ya tenías que dejarlo descansar. Pero tuvimos que superar esa fase y decir, "bueno, es parte de la historia y hay que recordarlo con dignidad”. Hubo antropólogos que decían que nosotros lo único que cargábamos era un espejo, que lo único que le estábamos enseñando a la gente es, "mírate aquí nada más", o sea, "esto es un espejo y mírate, nada más”. Esa fase la superamos [pues] no era un espejo: estábamos dejando la historia de un pueblo, de nuestras personas, nuestras gentes, y la historia de una cultura. Me queda muy claro que el cine tiene una función importante, que es dejar un precedente de la existencia de un pueblo, de un país tan diverso como es México, que existen diferentes lenguas, diferentes formas de expresión, física y corporal. Eso es lo que hemos aprendido y, sobre todo, que le pusimos sagrado porque es un espacio de reflexión.

\section{AC - Finalmente, ¿algo que quisieras agregar que no te haya preguntado?}

GR - Hemos reflexionado mucho sobre este proyecto porque es necesario retomarlo: no podemos partir de cero, tenemos que aprovechar, en nuestro caso, treinta años de experiencia de intenso trabajo en común, incorporando a todos, a toda la comunidad, las autoridades, nuestra familia, los que hicimos el equipo técnico, pues nos dimos cuenta de que ha valido la pena trabajar en nuestra historia. Allí están las memorias, allí están los registros y hoy hemos aprendido a leerlo de otra manera. Eso es lo interesante: que el proyecto sea leído pues se ha escrito mucho sobre esta experiencia, y se tiene que retomar porque ya es una experiencia de muchos años y hay que volver a darle vida y sentido. 


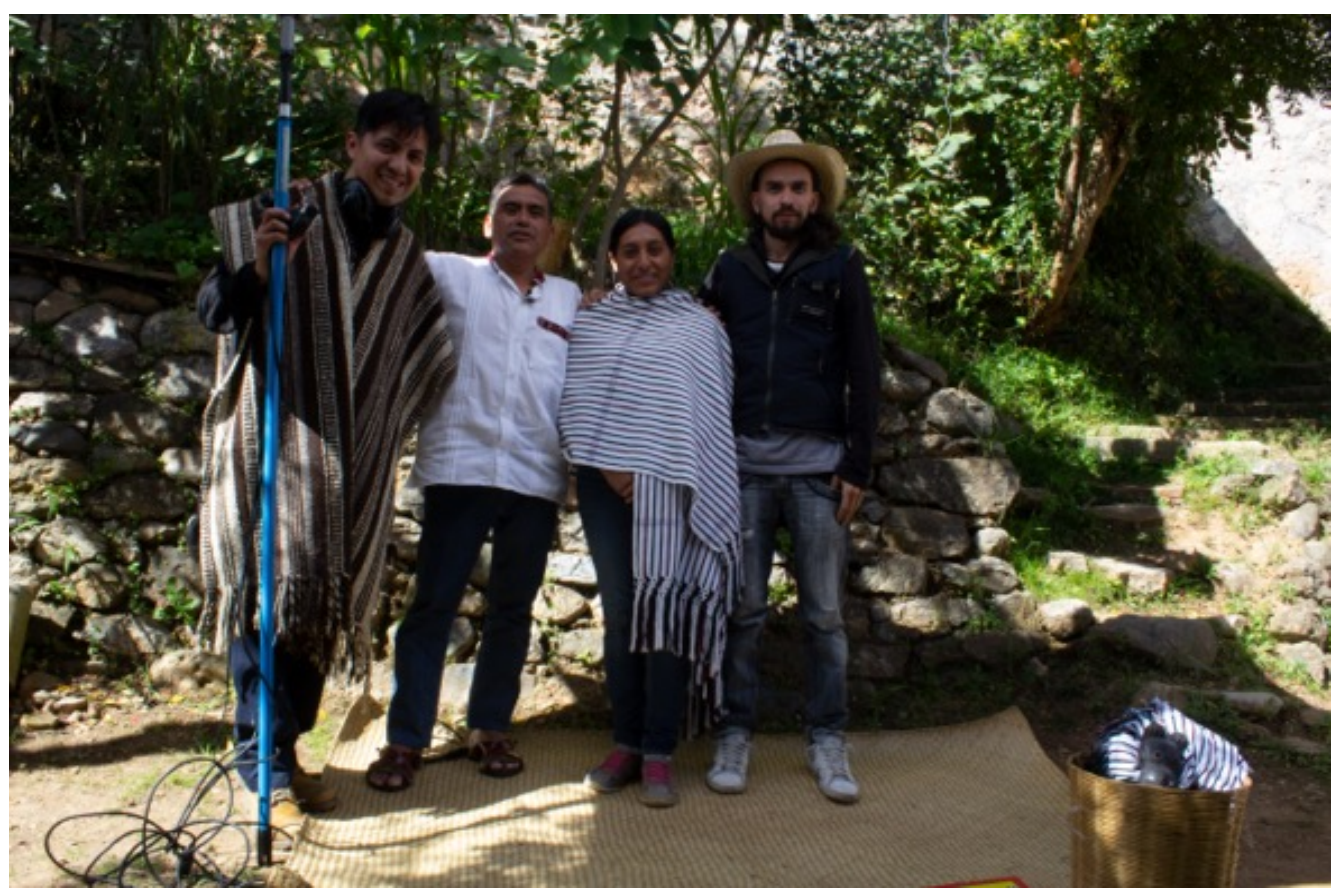

Imagen 6: De izquierda a derecha: el investigador Alberto Cuevas, el videasta mixe Genaro Rojas, la investigadora mixe Rosa Román y el videofotógrafo Aarón Álvarez, en casa del entrevistado. | Colección Alberto Cuevas.

\section{Referencias}

Anaya, Graciela, ed. 1990. Hacia un vídeo indio. México: INI Cuadernos 2 Archivo Etnográfico Audiovisual.

Barrera, Edith. 2017. "La resistencia de los pueblos Mixes de Tamazulápam del Espíritu Santo y Santa María Tlahuitoltepec.” Vínculos: Sociología, análisis y opinión 11 (Julio-diciembre): 153175.

Cuevas, Alberto. 2021. "Del AEA a la Transferencia de Medios Audiovisuales: un cambio de paradigma en el ocaso del INI.” En: Redescubriendo el Archivo Etnográfico Audiovisual, editado por Antonio Zirión, 387-411. México: UAM/Secretaría de Cultura. . 2020. "Historia y análisis del vídeo indígena en México. Transferencia de medios audiovisuales a organizaciones y comunidades indígenas, 1989-1994." Tesis de maestría. Ciudad de México: Universidad Nacional Autónoma de México (UNAM). 
Escuela Normal Rural Mactumactzá (ENRM). Sin fecha. "Conócenos." Consultado el 03 de diciembre, 2021. https://normalruralmactumactza.com/.

Instituto Nacional Indigenista (INI). 1991. "El Instituto Nacional Indigenista convoca a las organizaciones económicas indígenas al segundo curso." Fuente primaria ubicada en Archivo TV Tamix, Tamazulápam del Espíritu Santo Mixe, Oaxaca.

Primer Encuentro Nacional sobre Reescritura Tecnológica en México. 2016. "Genaro Rojas Ramírez." Consultado el 12 de julio de 2021. https://reescrituratecnologicamx.wordpress.com/genaro-rojasramirez/.

Secretaría Ejecutiva CNDH. Sin fecha. "Insurgencia del Ejército de Liberación Nacional (EZLN)." Consultado el 03 de diciembre, 2021. https://www.cndh.org.mx/noticia/insurgencia-delejercito-zapatista-de-liberacion-nacional-ezln.

\section{Filmografía}

En clave de sol [cortometraje, $35 \mathrm{~mm}$ ]. Dir. Ludwik Margules. Instituto Nacional Indigenista, México, 1981. 27 mins.

Fiesta animada [cortometraje, video analógico]. Dir. TV Tamix. México, 1994. 22 mins.

Jaripeo [cortometraje, video analógico]. Dir. TV Tamix. México, 1992. 3 mins

Këdung Ajdk (Servir al pueblo) [cortometraje, video analógico]. Dir. Hermenegildo Rojas. México, 1999. 26 mins.

Moojk (Maíz) [cortometraje, video analógico]. Dir. TV Tamix. México, 1996. 20 mins.

Peleas de tigres. Una petición de lluvia nahua [mediometraje, $35 \mathrm{~mm}$ ]. Dirs. Alfredo Portilla y Alberto Becerril, 1987. 60 mins. 


\title{
30 Years of TV Tamix: Interview with Genaro Rojas Ramírez, ayuujk video artist from Tamazulápam del Espíritu Santo, Oaxaca, founder of communitarian broadcaster TV Tamix
}

\begin{abstract}
Toward 1990, TV Tamix emerged in Tamazulapam del Espíritu Santo Mixe municipality, in the state of Oaxaca, Mexico. It was integrated by people with an interest in using and handling radio, video and television media. With video cameras, edition islands and an analogical postproduction center, the organization members registered their cultural manifestations. For broadcasting the video registers, they repaired an abandoned television transmitter that belonged to Instituto Mexicano de Television (Mexican Institute of Television, IMEVISION), giving rise to channel 12 "TV Tamix", an indigenous communication media spoken in ayuujk language.
\end{abstract}

KEYW ORDS Indigenous audiovisual; Mexico; television; TV Tamix.

\section{0 anos de TV Tamix: Entrevista a Genaro Rojas Ramírez, videasta ayuujk de Tamazulápam del Espíritu Santo, Oaxaca, fundador da televisão comunitária TV Tamix}

RESUmo Em 1990, foi fundada a TV Tamix no município de Tamazulápam del Espíritu Santo Mixe, Oaxaca. Nela participaram pessoas interessadas na utilização e gestão de média como rádio, vídeo e televisão. Com câmaras de vídeo, ilhas de edição e um centro analógico de pós-produção, os membros da organização registaram as suas manifestações culturais. Para transmitir os registos audiovisuais, repararam um transmissor de televisão que pertencia ao Instituto Mexicano de Televisão (IMEVISION), dando origem ao canal 12 "TV Tamix", um média indígena em língua ayuujk.

PALAVRAS-CHAVE Audiovisual indígena; México; televisão; TV Tamix.

aniki Entrevistas | Interviews 